\title{
Return to the Isle of Ted: Simulating the Collective Action Problem of Climate Change
}

Jocelyn Sage Mitchell, Northwestern University in Qatar

ABSTRACT This article modifies the classic "Isle of Ted" simulation to teach students about the collective action problems associated with climate change. Modifications include the introduction of a common-pool resource (i.e., fish) and increased pirate attacks to model rising climate threats and unequal distribution of risk. A return to the Isle of Ted enables a deeper engagement with specific collective action problems of climate change, including the tragedy of the commons and issues of global inequality. This article provides a road map for the incorporation of this modified simulation into active-learning classrooms.

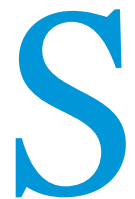

imulations are a popular pedagogical technique in political science classrooms for their ability to increase student engagement and promote active-learning experiences (Glazier 2011; Kerevel, Hultquist, and Edwards 2017; Mosinger 2019; Pallister 2015). A classic simulation is Thomas's (2002) "Isle of Ted"-a collective-action simulation used to teach students about public goods, free riding, anarchy, international organization, transparency, unequal power and resource distribution, and absolute-versus-relative gains.

This article describes the original Isle of Ted simulation and then explains modifications that teach students about specific collective action problems associated with climate change. One modification is the addition of a common-pool resource (i.e., fishing) as a way to increase a group's points, which allows students to experience the tragedy of the commons as the resource is exploited. Another modification is an increase in pirate attacks as the rounds progress, which models the rising threats of climate change on a global scale, as well as the unequal distribution of risk experienced by countries that are more vulnerable to its environmental effects.

This modified simulation was conducted in a sophomore class of 100 students at Northwestern University's campus in Doha, Qatar, as part of our interdisciplinary "Ways of Knowing: Climate Change" course. ${ }^{1}$ Implementation, discussion, and assessments from fall 2018 and fall 2019 demonstrate how this updated Isle of Ted simulation highlights issues specifically related to climate change.

Global climate change is an international collective action problem (Keohane 2015). Adaptation of the Isle of Ted to more fully engage with specific collective action problems of climate changeincluding common-pool resources, global inequality, and early and

Jocelyn Sage Mitchell ${ }^{(\mathbb{D})}$ is assistant professor in residence in the liberal arts program at Northwestern University in Qatar. She can be reached at jocelyn.mitchell@northwestern.edu. late development-both refreshes a classic simulation and adds to our pedagogical toolbox in political science classrooms.

\section{THE SIMULATION}

As in the original simulation, the instructor randomly assigns students to six different territories on the fictitious "Isle of Ted" (see map, figure 1). Students begin the game with a rule sheet (figure 2), a team record sheet (figure 3), and 10 points for each group. The instructor explains the rules; however, per Thomas $(2002,555)$, the goal of the game is "intentionally vague," and the suggestion to keep decisions secret for "deception" purposes strengthens postsimulation discussions of anarchy and transparency. Once students have a general idea of gameplay, the groups meet in separate areas of the classroom to plan their strategies.

The modified Isle of Ted simulation retains the original means of spending and gaining points. Groups may spend points in each round on road building or maintenance, which provides the opportunity to earn points through trade. Eight points are required to build the isle's road; after this common good is created, one point per round maintains this road for the benefit of all. Groups also may spend points on communal defense to protect against the pirate attack that occurs at the end of each round. This defense must equal or surpass the pirate attack-a variable number from one to four-to protect the four coastal groups from a loss of points. The defense "fund" must be replenished after each round.

I also maintained the original power imbalances of different groups on the isle. Their inland location protects two of the six territories from pirate attacks. Thus, these two groups have little incentive to contribute to the common defense and can use their points for other gains. In addition, two territories (both coastal) gain more points from trading on an established road than the other four. This trading advantage gives these two groups a 
higher stake in building and maintaining the road because it gives them twice as many points.

The simulation time required varies depending on the number of students. Ten rounds of play are ideal, but as long as the last round is announced in advance-to allow for end-game decision-making if the collective defense is insufficient. Both the roads and defense represent public goods from which all groups benefit regardless of their contribution, creating a prisoner's dilemma of free riding. In free riding, public goods are ruined not because the resources are overused but rather because of the lack of individual contributions

\section{Adaptation of the Isle of Ted to more fully engage with specific collective action problems of climate change-including common-pool resources, global inequality, and early and late development-both refreshes a classic simulation and adds to our pedagogical toolbox in political science classrooms.}

strategies-the number of rounds can be shortened due to time constraints. With 70 to 100 students, the modified simulation took approximately 80 minutes, followed by discussion. ${ }^{2}$

\section{THE MODIFICATIONS}

The two major modifications to the Isle of Ted are (1) the introduction of fish as a common-pool resource, and (2) the ability to increase the strength and frequency of pirate attacks over time.

\section{Fishing Boats}

The original Isle of Ted placed six groups on the island with the ability to gain points through trade on a road system, if built and maintained, and the chance to lose points through pirate attacks,
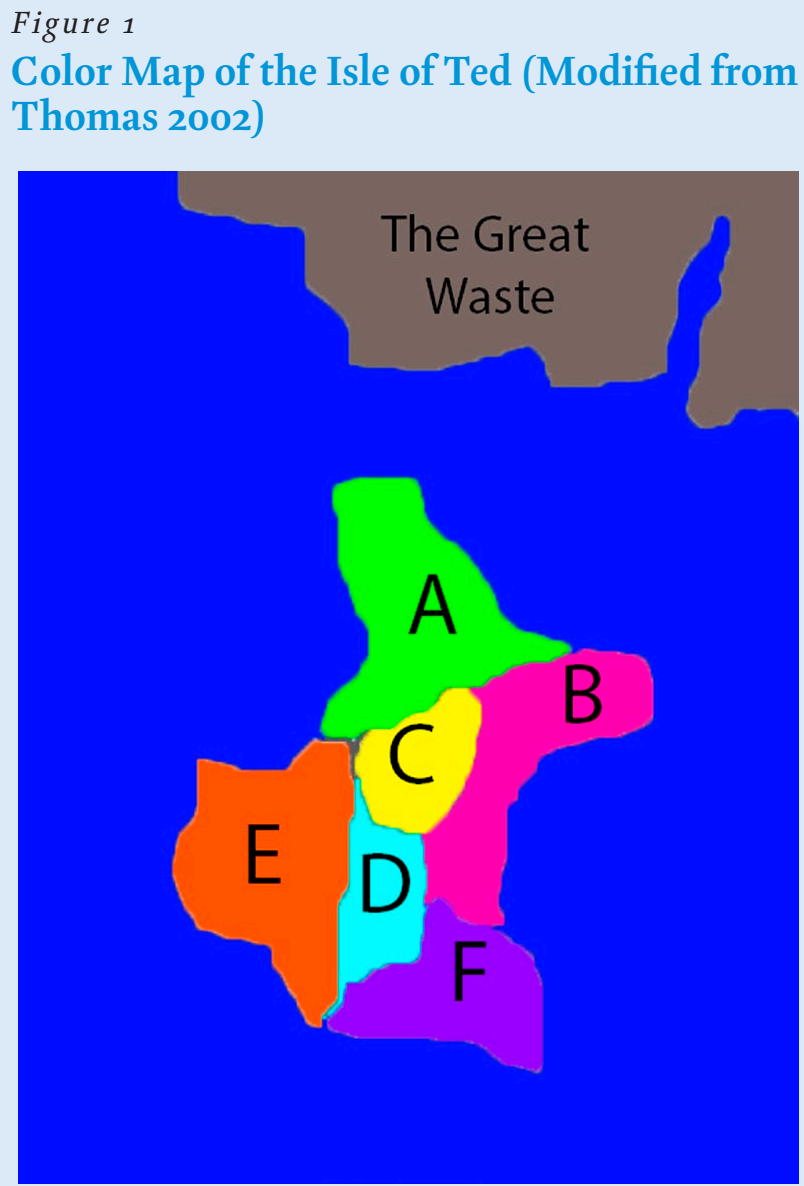

to the maintenance of this good. However, the original Isle of Ted does not have a common-pool resource-a good that is nonexclusive but limited in quantity. Common-pool resources such as forests, oceans, and the atmosphere are susceptible to the prisoner's dilemma known as the tragedy of the commons: that is, when rational individuals consume a publicly accessible, limited resource in unsustainable ways, leading to the destruction of the resource (Hardin 1968; Ostrom 1990).

In Isle of Ted: Climate Change, I added a common-pool resource by introducing fishing as a second way to gain points. The inclusion of fishing as a common-pool resource enables students to simulate and, later, to discuss specific climate change issues, such as overuse and depletion of common environmental goods. At the beginning of each turn, each group may send between zero and four fishing boats out to sea. Similar to decisions on roads and defense, each group's fishing decision is kept secret from the other groups. Each boat costs one resource point; each fish returned also equals a resource point. Before the simulation begins, the groups are told that the exact fishing haul per round is variable and that points gained by fishing accrue to individual groups and are not shared across the isle. A feature that is not announced in class but that becomes obvious as the simulation progresses is that the fish are limited in quantity. Therefore, the rate of return (calculated round-by-round by the instructor using an Excel spreadsheet) diminishes with overfishing.

Figure 4 depicts the instructor's Excel spreadsheet, which begins with a fish population of 200 . The rate of return is set as the current fish population divided by 100; therefore, round 1 gives a rate of return of two fish for every one boat (2:1). After the fishing haul is subtracted from the fish population, the fish naturally regenerate by $15 \%$ of the current population every round.

It is possible to fish sustainably from the beginning of the simulation. Figure 5 depicts a situation in which all groups send out only one boat each per turn. This farsighted collective action would result in an ever-increasing rate of return as the fish population regenerates beyond what is being fished each turn, so that by round 5 , the fishing-boat investment of one point returns three points of fish rather than two (i.e., a return of 3:1). However, I have not yet seen a class successfully pursue this prudent fishing scenario.

Gradual overfishing of the common-pool resource also can occur in this simulation. Figure 6 depicts the group choices in the fall 2019 class. The first-round fishing haul was a lucrative ratio of 2:1 (i.e., one boat=two "fish" or resource points), resulting in an enthusiastic embrace of fishing by all groups in rounds 2 and 3 . Signals of resource depletion were communicated to the class in 


\section{The Isle of Ted}

Rules Sheet

Summary of Game Play: For this exercise, your group represents one of the six groups on the Isle of TedAlpha, Beta, Cain, Delta, Eagle, or Frost. Score will be kept for each country (each begins with 10 resource points). There is no limit to the number of points a group can amass, but no group can go below o. Groups can use points to build a system of roads throughout the island to be used for trade, to send out fishing boats, or to provide for coastal defense. Points can be gained by trading or fishing. Groups lose points if they are successfully attacked by pirates.

Pirate Attacks: One to four raiding parties will randomly attack at least one of the four coastal groups (Alpha, Beta, Eagle, or Frost) each turn. To defeat the attack, the island must have a defense strength equal to or greater than the number of raiding parties; therefore, you may want to negotiate with your neighbors for support (defense strength $=$ resource points spent on defense). Each point spent on defense counts for the island as a whole"One for all, and all for one!" Each raiding party will carry off one resource point from the country they attack unless they are defeated. Both the number of raiding parties and the country to be attacked will be determined at random. The two groups who are at C and D (Cain and Delta) on the map cannot be attacked unless a neighboring coastal country is attacked and is out of points.

Trade: Each turn that a road network exists on the Isle of Ted, groups gain points depending on their locations on the map. The road network covers the entire island. Therefore, groups gain points whether or not they help build or maintain the road network. These are the additional points per turn each country gets when a road network is built:

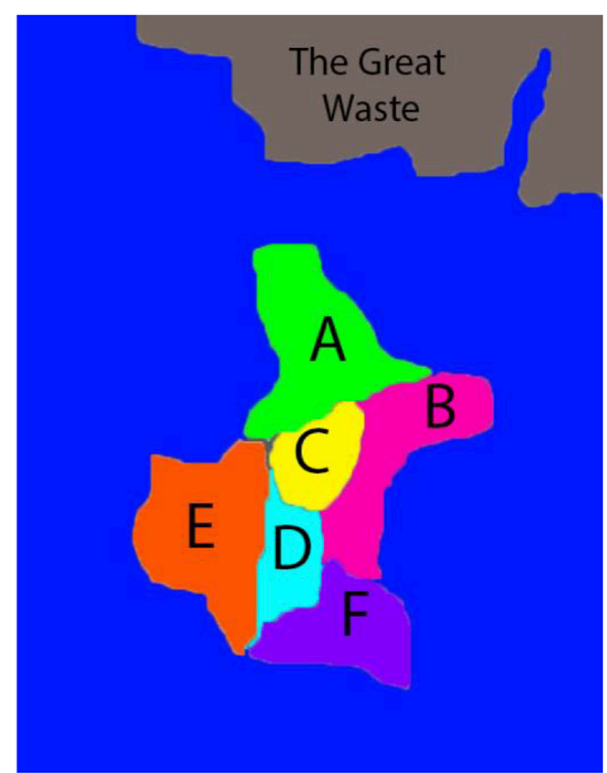

Figure 1. Map of the Isle of Ted
A (Alpha): 2 resource points
C (Cain): 1 resource point
B (Beta): 1 resource point
D (Delta): 1 resource point
E (Eagle): 2 resource points
F (Frost): 1 resource point

A road costs an initial 8 resource points to build and 1 resource point per turn thereafter to maintain. The cost of building a road may be shared among groups. Points spent on building the road network will carry over until a total of 8 points is reached. Any points spent in excess of 8 will be lost, and any points spent in excess of the one point necessary to maintain the roads will also be lost. If the road network is not maintained, a further 8 points will be necessary to rebuild the road network.

Fish: Each group may decide to send 1-4 fishing boats out to sea. Each boat costs 1 resource point. The more fish you catch, the more points you get! The points for fishing accrue to each group and are not shared with the whole island. The fishing haul will be announced at the end of each round.

Notes: We will go through several turns. The first turn will consist of three minutes of negotiation within groups. No discussion between groups can take place during the first turn. Thereafter, negotiations between groups will be allowed during the three-minute period. At the end of all turn negotiations each groups' choices must be handed in. The moderator will reveal whether or not roads have been built or maintained, how many boats were sent out and how much fish was caught, and also the total points spent on defense. The results of the trade, fishing, and pirate attacks will then be tallied. Hand in your decisions on the given sheet of paper. They will be kept secret. No one will know who contributed to the defense of the island or to the building of roads, or how many boats you sent. In fact, you may find deception a useful technique for preserving your points. 
round 3, when four boats produced seven points of fish instead of eight and three boats produced five points instead of six. This reduced fishing haul signaled that the good was being overused, and many of the groups responded by voluntarily reducing their fishing fleets for the next two rounds. However, because the common-pool resource was still being overused beyond the point led to rapid resource depletion, so that in rounds $5-7$, most fishing excursions received a 1:1 fishing haul. By round 9, threeand four-boat strategies resulted in an overall loss of points from investment to return, signaling the destruction of the resource. Group behavior after receiving the initial signals of depletion contributed to a useful postsimulation discussion about individual

\section{The inclusion of fishing as a common-pool resource enables students to simulate and, later, to discuss specific climate-change issues, such as overuse and depletion of common environmental goods.}

of regeneration, the fishing haul continued to decrease. In the face of this gradual depletion, some groups-bending to the logic of the tragedy of the commons-sought to maximize their fishing hauls by sending full fleets. Although the simulation ended before the fish population was drastically depleted, group behavior after receiving the first signal of depletion was a useful source of postgame discussion. Some groups recognized the resource exploitation and sought to moderate their use of it, whereas others sought to maximize their points before the resource ran out.

Figure 7 depicts the group choices in the fall 2018 class as an example of rapid overfishing. The difference is in the class reaction to the first signal of depletion. In this case, as the logic of the tragedy of the commons predicts, each group acted on its incentive to maximize individual benefits before the resource ran out. Despite receiving initial signals of depletion as early as round 2, the number of fishing boats increased each round. These actions incentives that drive the tragedy of the commons, along with discussions of "early" versus "late" fishers.

\section{Increase in Pirate Strength and Frequency of Attacks}

The original Isle of Ted retained the same pirate attack for each round of the game: a variable roll between one and four points, which would have to be defended against with the same or higher number of points on defense. If the pirates overcame the isle's defenses in that round, one of the four coastal groups (randomly chosen) would lose the number of points wielded by the pirates. The communal defense, from which all could benefit without contributing, is a useful example of a public good that can be lost due to the prisoner's dilemma of free riding. In addition, the unequal distribution of risk-in which the four coastal groups are directly vulnerable to attack whereas the two inland groups are not-promotes discussion of how conflicting interests lead to lack of consensus over a common goal.

Figure 3

Team Record Sheet and Example

The Isle of Ted Record Sheet: TEAM ALPHA
\begin{tabular}{|c|c|c|c|c|c|c|c|}
\hline Turn & $\begin{array}{c}\text { Cost of } \\
\text { Roads }\end{array}$ & $\begin{array}{c}\text { Gains from } \\
\text { Trade }\end{array}$ & $\begin{array}{c}\text { Fishing } \\
\text { Boats }(1-4)\end{array}$ & $\begin{array}{c}\text { Gains } \\
\text { from Fish }\end{array}$ & $\begin{array}{c}\text { Cost of } \\
\text { Defense }\end{array}$ & $\begin{array}{c}\text { Loss from } \\
\text { Pirates }\end{array}$ & $\begin{array}{c}\text { Current } \\
\text { Resources }\end{array}$ \\
\hline START & 0 & $0 /+2$ & 0 & $?$ & 0 & 0 & 10 \\
\hline 1 & & & & & & & \\
\hline 2 & & & & & & & \\
\hline$\ldots$ & $\ldots$ & $\ldots$ & $\ldots$ & $\ldots$ & $\ldots$ & $\ldots$ & $\ldots$ \\
\hline 9 & & & & & & & \\
\hline 10 & & & & & & & \\
\hline
\end{tabular}

Example: On turn 1, Team $\Lambda$ lpha spent 1 point on building roads, 3 points on fishing boats, and 1 point on defense. These points are subtracted from Alpha's starting resources, but Alpha also received 6 points from the fishing haul, resulting in a total of 11 points. On turn 2, a road network is built, which gave Alpha a gain of 2 points from trade. Alpha spent 1 point on maintaining the road, 3 points on fishing boats, and 1 point on defense. The fishing boats again brought in 6 points, giving Alpha 14 total points. On turn 3, Alpha spent 1 point on maintaining the road (resulting in 2 points from trade), 2 points on fishing boats (resulting in a fishing haul of 3 points), but did not contribute to defense. Alpha lost 3 points to the pirate attack, as the Isle's combined defenses were less than 3. This leaves Alpha with a total of 13 points at the end of turn 3 . Note that this is just an example, representing one possible strategy and outcome.

\begin{tabular}{|c|c|c|c|c|c|c|c|}
\hline Turn & $\begin{array}{c}\text { Cost of } \\
\text { Roads }\end{array}$ & $\begin{array}{c}\text { Gains from } \\
\text { Trade }\end{array}$ & $\begin{array}{c}\text { Fishing } \\
\text { Boats }(1-4)\end{array}$ & $\begin{array}{c}\text { Gains } \\
\text { from Fish }\end{array}$ & $\begin{array}{c}\text { Cost of } \\
\text { Defense }\end{array}$ & $\begin{array}{c}\text { Loss from } \\
\text { Pirates }\end{array}$ & $\begin{array}{c}\text { Current } \\
\text { Resources }\end{array}$ \\
\hline START & 0 & $0 /+2$ & 0 & $?$ & 0 & 0 & 10 \\
\hline 1 & 1 & 0 & 3 & 6 & 1 & 0 & 11 \\
\hline 2 & 1 & 2 & 3 & 6 & 1 & 0 & 14 \\
\hline 3 & 1 & 2 & 2 & 3 & 0 & 3 & 13 \\
\hline
\end{tabular}


The pirates in the modified Isle of Ted: Climate Change serve an additional pedagogical purpose: to symbolize the increasing threats of climate change over time. Regarding the "wicked problem" of climate change (Incropera 2016), the environmental impacts (and socioeconomic solutions) increase over time in terms of threat and expense. It is useful for a discussion of collective action problems surrounding climate change to include a component that acknowledges the increase over time of carbon dioxide and other greenhouse gases in our atmosphere and its concurrent impacts on severe weather events and rising temperatures and seas (Romm 2018). To simulate this increasing threat, as well as the rising costs of adaptation and mitigation, I introduced a modification that allows the instructor to increase the number and strength of the pirate attacks over time. This threat occurs at the instructor's discretion, so it can be used at key moments in the simulation to (1) disrupt existing collective action that so far is successfully defending the isle; (2) spur greater interest in contributing to the common defense; and (3) simulate the larger economic impact of exponential (and unpredictable) threat increases. It also emphasizes the point that some groups are more vulnerable to the escalating intensity of the pirates (and, by extension, the increasing effects of climate change) than others.

The instructor's flexibility-in deciding when to implement stronger pirate attacks and whether attacks affect multiple groups or a single target-is useful for the simulation. After an initial successful pirate attack in round 2, the fall 2018 class created a common-defense coalition, which successfully repelled additional attacks in rounds $3-5$. To disrupt this defense coalition, I initiated two groups of pirates attacking separate groups in round 6, which led to a successful pirate attack that took three points each from two territories. Because the attacks were distributed among multiple coastal groups, these groups had more incentive to coordinate for the common defense; they again successfully repelled attacks in rounds $7-8$. In the final round of play, I expanded the

Figure 4

Fishing Haul: Pre-Game Excel Spreadsheet

FISH POPULATION CALCULATION (PER TURN)

\begin{tabular}{|c|c|c|c|c|c|}
\hline Turn & Fish Population & Rate of Return & Number of Boats & Total Fish Caught & Final Population \\
\hline 1 & 200 & 2.0 & & 0 & 200 \\
\hline 2 & 230 & 2.3 & & 0 & 230 \\
\hline 3 & 265 & 2.6 & & 0 & 265 \\
\hline 4 & 304 & 3.0 & & 0 & 304 \\
\hline 5 & 350 & 3.5 & & 0 & 350 \\
\hline 6 & 402 & 4.0 & & 0 & 402 \\
\hline 7 & 463 & 4.6 & & 0 & 463 \\
\hline 8 & 532 & 5.3 & & 0 & 532 \\
\hline 9 & 612 & 6.1 & & 0 & 612 \\
\hline 10 & 704 & 7.0 & & & 704 \\
\hline
\end{tabular}

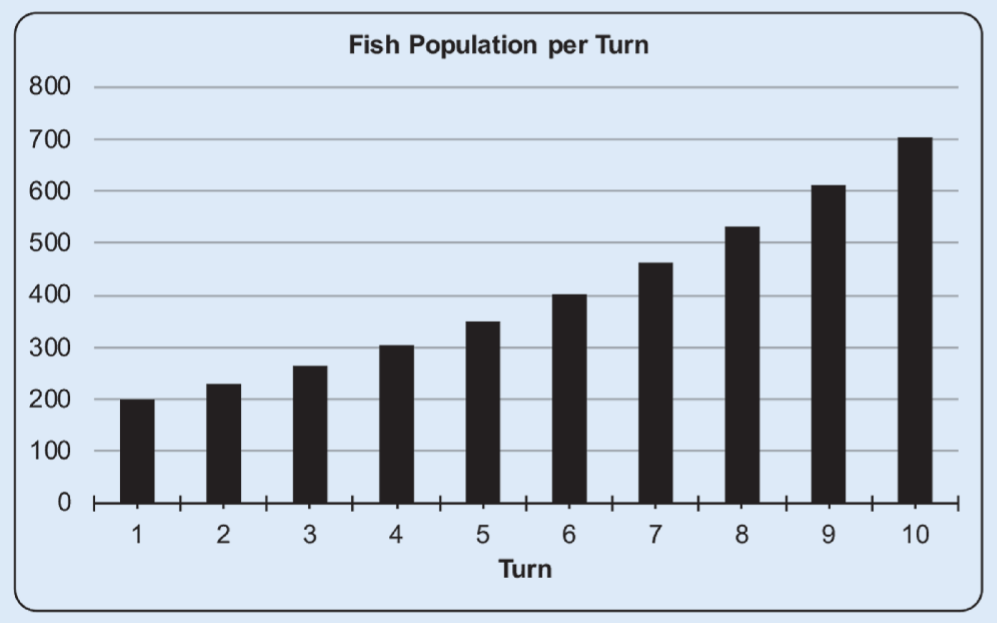

FISHING RATE OF RETURN CALCULATION (PER TURN)

\begin{tabular}{|c|r|r|r|r|}
\hline Turn & 1 Boat & 2 Boats & 3 Boats & \multicolumn{1}{|c|}{ 4 Boats } \\
\hline 1 & 2 & 4 & 6 & 8 \\
\hline 2 & 2 & 5 & 7 & 9 \\
\hline 3 & 3 & 5 & 8 & 12 \\
\hline 4 & 3 & 6 & 9 & 14 \\
\hline 5 & 3 & 7 & 10 & 16 \\
\hline 6 & 4 & 8 & 12 & 19 \\
\hline 7 & 5 & 14 & 21 \\
\hline 8 & 5 & 11 & 16 & 24 \\
\hline 9 & 5 & 12 & 18 & 28 \\
\hline 10 & 6 & 14 & 21 & \\
\hline
\end{tabular}


Figure 5

Fishing Haul: Example of Sustainable Fishing Scenario

FISH POPULATION CALCULATION (PER TURN)

\begin{tabular}{|c|c|c|c|c|c|}
\hline Turn & Fish Population & Rate of Return & Number of Boats & Total Fish Caught & Final Population \\
\hline 1 & 200 & 2.0 & 6 & 15 & 185 \\
\hline 2 & 213 & 2.1 & 6 & 16 & 197 \\
\hline 3 & 226 & 2.3 & 6 & 17 & 209 \\
\hline 4 & 241 & 2.4 & 6 & 18 & 223 \\
\hline 5 & 256 & 2.6 & 6 & 20 & 237 \\
\hline 6 & 272 & 2.7 & 6 & 22 & 252 \\
\hline 7 & 290 & 2.9 & 6 & 23 & 268 \\
\hline 8 & 308 & 3.1 & 6 & 25 & 285 \\
\hline 9 & 328 & 3.3 & 6 & 26 & 303 \\
\hline 10 & 349 & 3.5 & 6 & & 323 \\
\hline
\end{tabular}

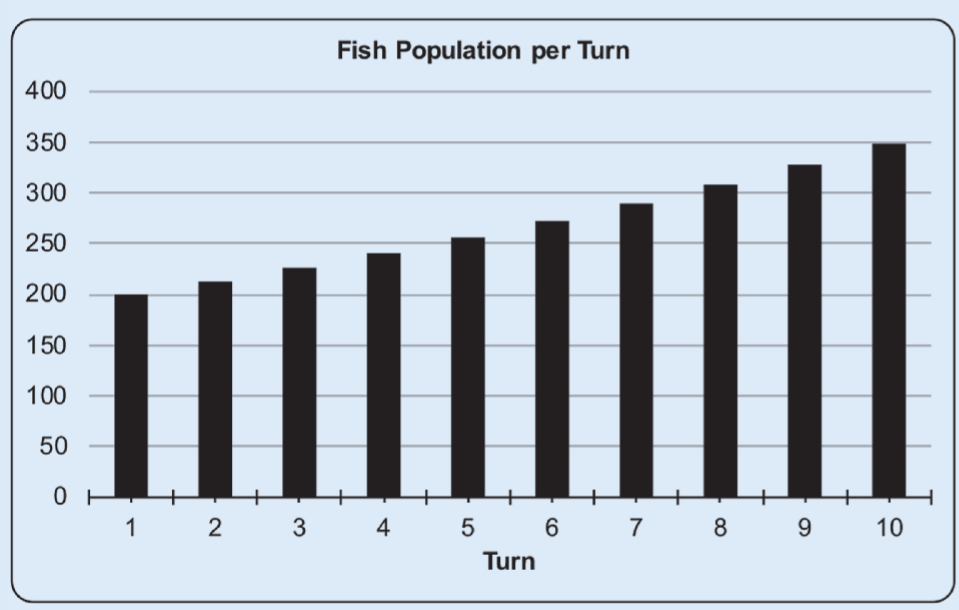

FISHING RATE OF RETURN CALCULATION (PER TURN)

\begin{tabular}{|c|r|r|r|r|}
\hline Turn & 1 Boat & 2 Boats & 3 Boats & 4 Boats \\
\hline 1 & 2 & 4 & 6 & 8 \\
\hline 2 & 2 & 4 & 6 & 9 \\
\hline 3 & 2 & 5 & 7 & 9 \\
\hline 4 & 2 & 5 & 7 & 10 \\
\hline 5 & 3 & 5 & 8 & 10 \\
\hline 6 & 3 & 5 & 8 & 11 \\
\hline 7 & 3 & 6 & 9 & 12 \\
\hline 8 & 3 & 6 & 9 & 12 \\
\hline 9 & 3 & 7 & 10 & 13 \\
\hline 10 & 3 & 7 & & 10 \\
\hline
\end{tabular}

pirates to three raiding parties, defense coordination broke down, and three territories lost six points each to the pirates. The fall 2019 class successfully coordinated a defense coalition for several rounds until I announced in round 5 that the pirates would double in strength but remain focused on one group only per round. One of the coastal groups made the rational calculation to free ride on others' contributions, which led to a breakdown of the defense coalition and several successful pirate attacks. In this simulation, it was not necessary to further elevate the pirate intensity because students already were able to experience the increasing costs of collective action and the free-riding problem.

\section{Additional Modifications}

Further modifications included (1) removing the cap on points (originally set at 20 per group) to simulate free-market capitalism and encourage competition for points; and (2) increasing the time for negotiation between rounds from two to three minutes, which better allowed students to explore the promise and pitfalls of international organizations. Also, an online, four-sided die provided a clearer visual of the pirate attacks than two flipped coins. Lesson materials are available in this article and online. ${ }^{3}$

\section{DISCUSSION}

It is important to have time for discussion after the simulation to connect the activity to the course material and learning goals. In his original Isle of Ted simulation, Thomas (2002, 556-57) provided 12 useful discussion questions on a range of topics, including free riding, anarchy, international organizations, transparency, and game objective. The modifications in Isle of Ted: Climate Change allow the instructor to discuss these issues in more depth, particularly regarding collective goods and unequal distribution of risk.

Whereas the original Isle of Ted presented two types of public goods (i.e., roads and defense), the introduction of fishing 
Figure 6

\section{Fishing Haul: Example of Gradual Overfishing Scenario (Fall 2019)}

FISH POPULATION CALCULATION (PER TURN)

\begin{tabular}{|c|c|c|c|c|c|}
\hline Turn & Fish Population & Rate of Return & Number of Boats & Total Fish Caught & Final Population \\
\hline 1 & 200 & 2.0 & 14 & 35 \\
\hline 2 & 190 & 1.9 & 15 & 36 \\
\hline 3 & 177 & 1.8 & 18 & 40 \\
\hline 4 & 158 & 1.6 & 13 & 26 & \\
\hline 5 & 152 & 1.5 & 13 & 137 & 25 \\
\hline 6 & 147 & 1.5 & 15 & 132 & 27 \\
\hline 7 & 137 & 1.4 & 14 & & 24 \\
\hline
\end{tabular}

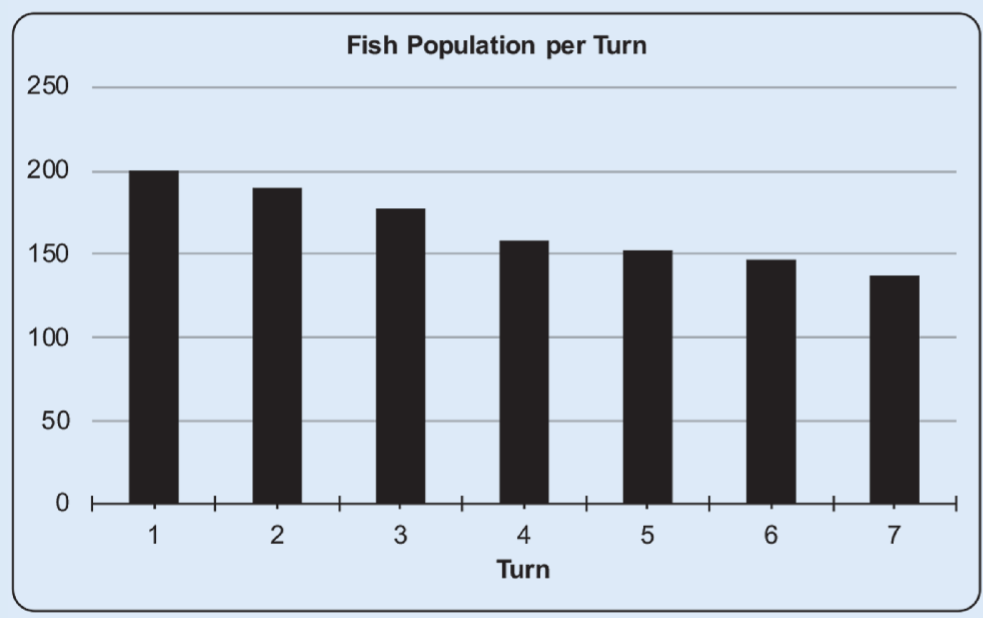

FISHING RATE OF RETURN CALCULATION (PER TURN)

\begin{tabular}{|c|r|r|r|r|}
\hline Turn & 1 Boat & 2 Boats & 3 Boats & 4 Boats \\
\hline 1 & 2 & 4 & 6 & 8 \\
\hline 2 & 2 & 4 & 6 & 8 \\
\hline 3 & 2 & 4 & 5 & 7 \\
\hline 4 & 2 & 3 & 5 & 6 \\
\hline 5 & 2 & 3 & 4 & 6 \\
\hline 6 & 1 & 3 & 4 & \\
\hline 7 & 1 & 3 & & \\
\hline
\end{tabular}

allowed for important debriefing discussions on two concepts that are essential for a larger understanding of the global politics of climate change. First, the introduction of fish prompted discussion of collective action problems associated with global access to common-pool resources. In particular, we discussed the importance of clear warning signals regarding environmental impact, the need to understand the cause and effect of these signals, and the difficulties in communicating this knowledge to multiple stakeholders as well as implementing a sustainable strategy to preserve the resource.

Second, we could discuss the ethical responsibilities of earlyversus-late developers (Klein 2014; Roberts and Parks 2007) because those groups that overfished in the early rounds gained more points than those who began to fish once the rate of return already was reduced. The simulation facilitated discussion of the concept of "common but differentiated responsibilities," one of the main principles of the UN Framework Convention on Climate Change (Betsill and Fiske 2020, 280-81). This principle places the larger responsibility to reduce emissions on industrialized and post-communist countries while allowing more leeway for developing countries such as China, India, and Brazil. The United
States objected to climate-change frameworks that adhere to this principle, such as the Kyoto Protocol and, more recently, the Paris Accords (Betsill and Fiske 2020, 297-98), making it of particular importance for understanding current debates on global climate policy.

The increased strength and frequency of pirate attacks highlighted the unequal distribution of risk in Isle of Ted: Climate Change, mirroring current discussions of ecological justice, vulnerability, and power in global environmental politics (Ciplet, Roberts, and Khan 2015; Conca and Dabelko 2018). An important facet of understanding current climate-change debates is recognizing the vulnerability of countries such as Bangladesh, the Netherlands, and the Maldives to environmental changes including heat waves, drought, and sea-level rise. The sudden increases in pirate attacks prompted a discussion of the exponential rise of greenhouse gases, the concurrent greater likelihood of extreme weather events, and-most important-which groups were vulnerable to these risks and which were protected. This discussion strengthened student understanding of unequal voice, power, and resources. We also discussed the impact of emotions including fear, despair, and 
injustice in the face of increasingly insurmountable challenges (Norgaard 2011).

\section{ASSESSMENT AND EVALUATION}

Two writing assignments reinforced the learning outcomes of the simulation. The first, a low-stakes, one-page assignment, served as both a formative comprehension check and a scaffold and readings to explain specific examples from the game. The second writing assignment asked them to demonstrate their understanding of collective action by introducing and defining these terms in their own words, applying this theoretical framework to the Isle of Ted simulation to explain the difficulties of social cooperation on climate change, and offering possible solutions.

The increased strength and frequency of pirate attacks highlighted the unequal distribution of risk in Isle of Ted: Climate Change, mirroring current discussions of ecological justice, vulnerability, and power in global environmental politics.

toward the second assignment, a four-page essay. The first assignment's prompt asked students to reflect on their experience playing the Isle of Ted, using collective action terms from lectures
In the writing assignments, students demonstrated that they could apply theoretical terms to specific aspects of gameplay. They reflected on the different types of goods (i.e., fish as the

Figure 7

Fishing Haul: Example of Rapid Overfishing Scenario (Fall 2018)

FISH POPULATION CALCULATION (PER TURN)

\begin{tabular}{|c|c|c|c|c|c|}
\hline Turn & Fish Population & Rate of Return & Number of Boats & Total Fish Caught & Final Population \\
\hline 1 & 200 & 2.0 & 16 & 40 & 160 \\
\hline 2 & 184 & 1.8 & 16 & 37 & 147 \\
\hline 3 & 169 & 1.7 & 16 & 34 & 135 \\
\hline 4 & 156 & 1.6 & 18 & 35 & 121 \\
\hline 5 & 139 & 1.4 & 21 & 36 & 102 \\
\hline 6 & 118 & 1.2 & 19 & 28 & 90 \\
\hline 7 & 103 & 1.0 & 21 & 27 & 76 \\
\hline 8 & 88 & 0.9 & 12 & 13 & 74 \\
\hline 9 & 86 & 0.9 & 16 & 17 & 68 \\
\hline
\end{tabular}

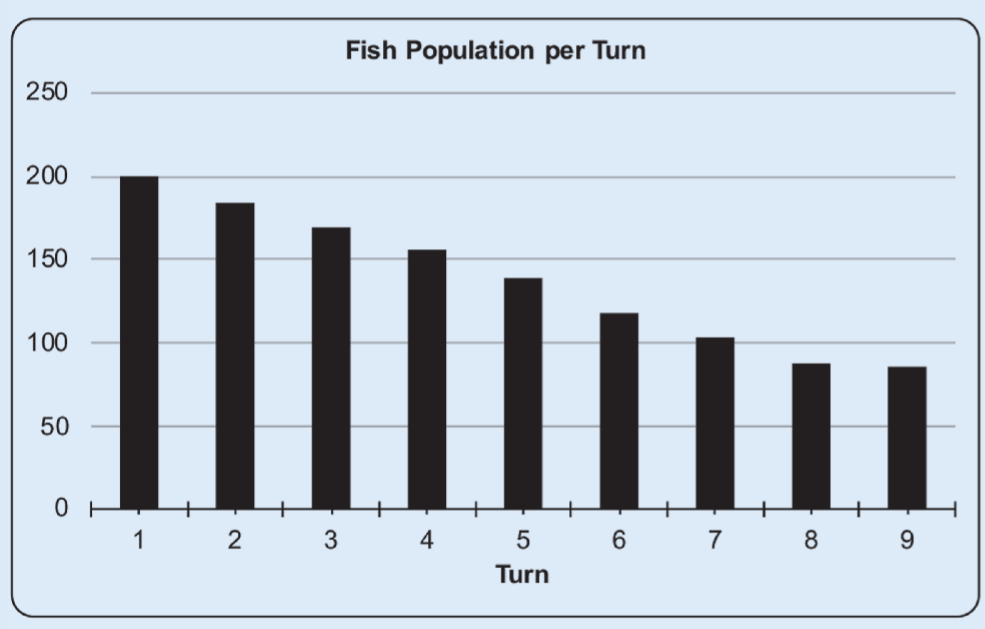

FISHING RATE OF RETURN CALCULATION (PER TURN)

\begin{tabular}{|c|c|c|c|c|}
\hline Turn & 1 Boat & 2 Boats & 3 Boats & 4 Boats \\
\hline 1 & 2 & 4 & 6 & 8 \\
\hline 2 & 2 & 4 & 6 & 7 \\
\hline 3 & 2 & 3 & 5 & 7 \\
\hline 4 & 2 & 3 & 5 & 6 \\
\hline 5 & 1 & 3 & 4 & 6 \\
\hline 6 & 1 & 2 & 4 & 5 \\
\hline 7 & 1 & 2 & 3 & 4 \\
\hline 8 & 1 & 2 & 3 & 4 \\
\hline 9 & 1 & 2 & 3 & 3 \\
\hline
\end{tabular}


common-pool resource; defense and roads as the public goods) and the specific prisoner's dilemmas that occurred with each type of good (i.e., tragedy of the commons and free riding, respectively). Answers also connected the increased strength of the pirates over time-which resulted in an increased threat level for all coastal groups and the need for more point allocation to defense--to the growing threat of environmental risk. Students related the issues encountered in the game to the problem of collective action as a whole, including coordination problems, lack of implementation strategies, and absence of a common goal. Most important, students were able to deploy collective action concepts to explain current political obstacles to climate change action and theorize possible solutions. As one student reflected in her essay, "Playing the Isle of Ted really opened my eyes and it made the terms that we've studied come to life....Even in one classroom, it was hard to coordinate, implement, and work together for a common good. Comparing this to the world we live in, it shows that we have a lot of work to do to fight against global problems like climate change."

\section{SUPPLEMENTARY MATERIAL}

To view supplementary material for this article, please visit https://doi.org/10.1017/S1049096519002221

\section{ACKNOWLEDGMENTS}

This simulation-and the course as a whole-is a result of much community support at Northwestern University in Qatar. I thank Christopher James Macintosh Sparshott, my co-professor in Ways of Knowing, for three years of development, innovation, and learning together; Sandra L. Richards for her leadership in our liberal arts program that led to the creation of this course; Scott Curtis for his pedagogical prowess and gentle but firm editing; and our students, who have helped improve Ways of Knowing every year with their interest, enthusiasm, and good humor. Nick Mitchell deserves special thanks as the originator of the fishing Excel spreadsheet! I also thank participants at TEACHx, Northwestern University, May 2019, and the panel, "Teaching Political Science: Using Simulations in the Classroom," American Political Science Association, August 2019, as well as anonymous reviewers for useful feedback. The publication of this article was funded by the Qatar National Library.

\section{NOTES}

1. This required sophomore-year course is on liberal arts epistemology: how different disciplines ask and answer questions about the world. The common theme of climate change serves as a concrete "mental hook" for student comprehension of the similarities and differences among disciplines. In addition to its usefulness as a tool for teaching epistemology, climate change is of existential importance for our students. Virtually all climate scientists agree that anthropogenic (i.e., manmade) climate change is due to increasing concentrations of greenhouse gases, particularly carbon dioxide, in our atmosphere (Romm 2018). The hydrocarbon-rich monarchy of Qatar has an outsized economic role in worldwide production, export, and consumption of oil and gas (Krane 2019). Yet, at the same time, future temperatures in the Persian Gulf are projected to "exceed a threshold for human adaptability" by the turn of the century (Pal and Eltahir 2016, 197). With Qatar's economic system dependent on hydrocarbon exports, learning about climate change may be politically fraught yet nevertheless essential for the future of the local community and the state as a whole.

2. The unwieldly nature of making decisions in a group of 10 to 16 is itself a learning experience for students. In their written assessments, they reflected on the collective action problem of free riding regarding group decisions because some students contributed more than others. Thus, this simulation can be useful in both small and large classrooms.

3. Downloadable lesson materials, including PDFs of the rules and team record sheets, a PowerPoint presentation, and the fishing Excel spreadsheet, are available in the supplementary material.

\section{REFERENCES}

Betsill, Michele M., and Desirée Fiske. 2020. "International Climate Change Policy: Complex Multilevel Governance." In The Global Environment: Institutions, Law, and Policy, 5th edition, ed. Regina S. Axelrod and Stacy D. VanDeveer, 271-304. Thousand Oaks, CA: CQ Press.

Ciplet, David, J. Timmons Roberts, and Mizan R. Khan. 2015. Power in a Warming World: The New Global Politics of Climate Change and the Remaking of Environmental Inequality. Cambridge, MA: MIT Press.

Conca, Ken, and Geoffrey D. Dabelko (eds.). 2018. Green Planet Blues: Critical Perspectives on Global Environmental Politics, 6th edition. Boulder, CO: Westview Press.

Glazier, Rebecca. 2011. "Running Simulations Without Ruining Your Life: Simple Ways to Incorporate Active Learning into Your Teaching." Journal of Political Science Education 7 (4): 375-93.

Hardin, Garrett. 1968. "The Tragedy of the Commons.” Science 162: 1243-48.

Incropera, Frank P. 2016. Climate Change: A Wicked Problem. New York: Cambridge University Press.

Keohane, Robert O. 2015. “The Global Politics of Climate Change: Challenge for Political Science.” PS: Political Science \& Politics 48 (1): 19-26.

Kerevel, Yann P., Philip Hultquist, and Margaret E. Edwards. 2017. "Multilevel Bargaining and the Negotiation of a Regional Trade Agreement: A Classroom Simulation." PS: Political Science \& Politics 50 (2): 576-80.

Klein, Naomi. 2014. This Changes Everything: Capitalism vs. the Climate. New York Simon and Schuster.

Krane, Jim. 2019. Energy Kingdoms: Oil and Political Survival in the Persian Gulf. New York: Columbia University Press.

Mosinger, Eric. 2019. "Control and Collaboration: Simulating the Logic of Violence in Civil War for Political Science Students." PS: Political Science \& Politics $52(3): 543-48$.

Norgaard, Kari Marie. 2011. Living in Denial: Climate Change, Emotions, and Everyday Life. Cambridge, MA: MIT Press.

Ostrom, Elinor. 1990. Governing the Commons: The Evolution of Institutions for Collective Action. Cambridge: Cambridge University Press.

Pal, Jeremy S., and Elfatih A. B. Eltahir. 2016. "Future Temperature in Southwest Asia Projected to Exceed a Threshold for Human Adaptability." Nature Climate Change 6: 197-200.

Pallister, Kevin. 2015. "Teaching Globalization and Development through a Simulation." PS: Political Science \& Politics 48 (2): 364-67.

Roberts, J. Timmons, and Bradley C. Parks. 2007. A Climate of Injustice: Global Inequality, North-South Politics, and Climate Policy. Cambridge, MA: MIT Press.

Romm, Joseph. 2018. Climate Change: What Everyone Needs to Know, 2nd edition. New York: Oxford University Press.

Thomas, G. Dale. 2002. "The Isle of Ted Simulation: Teaching Collective Action in International Relations and Organization." PS: Political Science E Politics 35 (3): 555-59. 